\title{
Research on the Intention of Use of Remote Monitoring Technology for the Elderly Based on Technology Acceptance Model
}

\author{
Xixian Zheng ${ }^{1}$, Haixia $\mathrm{Tan}^{2}$, Hebo $\mathrm{Lu}^{3, *}$ \\ ${ }^{1,2}$ School of Management, Yunnan Minzu University 2929 Yuehua Road, Chenggong District, Kunming, Yunnan \\ 650504, China \\ ${ }^{3}$ School of Management, Shanghai University 99 Shangda Road, Baoshan District, Shanghai 200444, China \\ *Email: JerryLu@shu.edu.cn
}

\begin{abstract}
As China's population ages, the safety of older adults living alone is a matter of social security and stability. Information technology-based remote monitoring technology for smart elderly care is of great concern to society. The article presents hypotheses based on a technology acceptance model and analyzes and tests the questionnaire data using SPSS19.0 and AMOS24.0 software. It was found that the perceived ease of use of remote monitoring technology had a significant positive effect on perceived usefulness; the perceived usefulness and perceived ease of use of remote monitoring technology had a significant positive impact on attitude; the perceived usefulness and attitude of remote monitoring technology had a significant positive effect on the intention of use; gender, age, education, and health status had a different impact on perceived usefulness, perceived ease of use The perceived ease of use is the most critical factor affecting the attitude of older adults toward remote monitoring technology. To facilitate companies to develop more applicable and straightforward remote monitoring technologies for the elderly, the article proposes corresponding suggestions from the perspective of product development direction and technology innovation strategy.
\end{abstract}

Keywords: Population Aging, Remote Monitoring Technology, Intention of Use, Technology Acceptance Model.

\section{INTRODUCTION}

The problem of the aging population in China has intensified. According to the Communique of the Seventh National Census, the total number of older adults aged 60 and above in the mainland was 264 million by the end of 2020 , accounting for $18.7 \%$ of the total population of the country. In the 20 years since 2000 , when we entered the aging society, the proportion of the elderly population has increased by 8.4 percentage points, and the issue of population aging has become a significant issue concerning the national economy and people's livelihood. To effectively cope with the social problems brought by population aging, the country has proposed the "9073" elderly care pattern [5], and the home care model is a mainstream elderly care model currently implemented. However, due to the physiological and cognitive dysfunction and reduced physical flexibility of the elderly, the elderly living alone face many problems [7]. Some studies have shown that the incidence of accidental injuries and fatalities among older adults at home are high [2] [13], and the safety of older adults at home cannot be ignored. With the development of information technology, smart home care technology has emerged. Remote monitoring technology can be used to monitor the daily activities of the elderly and the environmental safety status [5]. However, since most of the current older adults over 60 years old were born before the 1850 s, they are generally unfamiliar with modern information technology. It is difficult for them to accept and use it [3]. Therefore, in this paper, we investigate the elderly in Kunming to understand their intention to use remote monitoring technology to point out the development direction for related enterprises, as well as to provide valuable suggestions for improving the quality of evening life of the elderly. 


\section{THEORETICAL BASIS AND MODEL ASSUMPTIONS}

\subsection{Technology Acceptance Model}

The technology acceptance model (TAM) is a model constructed by American scholar Davis in 1989 based on the theory of reasoned action (TRA), which is one of the most widely used theories in the study of user acceptance behavior [1]. The model assumes that users' perceived usefulness and perceived ease of use of information technology affect their attitudes and thus their intention of use. In recent years, the research applications of the TAM model in smart aging mainly include the following two aspects: firstly, it is used to study the intention of older adults to a certain technology [8]. Secondly, it is used to explore factors that influence older adults' intention to accept a particular technology, such as perceived safety [4] and anxiety [6]. The theoretical model is shown in Figure 1.

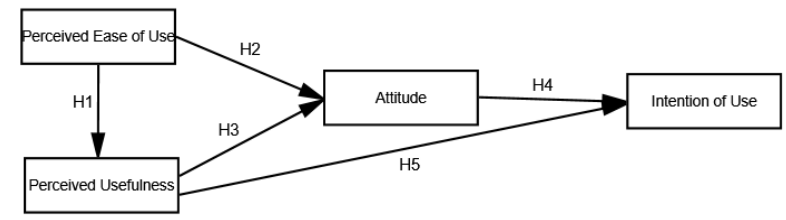

Figure 1. Technology acceptance model diagram

\subsection{Model Hypothesis}

According to the TAM model, perceived ease of use positively affects perceived usefulness and attitude. Perceived usefulness positively affects attitude and intention of use. Attitude positively affects intention of use. Many previous studies based on the technology acceptance model have confirmed their positive relationships [10] [11]. Therefore, based on the above theoretical analysis, the following hypotheses are proposed in this study.

H1: Older adults' perceived ease of use of remote monitoring technology positively influences their perceived usefulness.

H2: Older adults' perceived ease of use of remote monitoring technology positively influences their attitudes.

H3: Older adults' perceived usefulness of remote monitoring technology positively influences their attitudes.

H4: Older adults' attitudes toward remote monitoring technology positively influence their intention of use.

H5: The perceived usefulness of remote monitoring technology among the elderly positively influences their intention of use.

\section{RESEARCH DESIGN}

\subsection{Variable Measurement}

Since the latent variables in this study are not directly measurable, observable variables must be established to estimate them. To ensure the reliability and validity of the questionnaire, this study combines the characteristics of remote monitoring technology itself and draws on the observed variables commonly used in related studies at home and abroad, which are modified based on the expected survey. The specific measurement items and sources of each latent variable in this study are shown in Table 1.

Table 1 Variable measures and sources

\begin{tabular}{|c|c|c|}
\hline Variables & Measurement Items & $\begin{array}{c}\text { Referen } \\
\text { ces }\end{array}$ \\
\hline $\begin{array}{l}\text { Perceived } \\
\text { Ease of } \\
\text { Use }\end{array}$ & $\begin{array}{l}\text { PEOU1: How easy it is to learn } \\
\text { remote monitoring technology } \\
\text { PEOU2 : How easy it is to operate } \\
\text { remote monitoring technology } \\
\text { PEOU3 : Ease of access to } \\
\text { information by remote monitoring } \\
\text { technology } \\
\text { PEOU4 : The ease of use of remote }\end{array}$ & {$[1]$} \\
\hline $\begin{array}{l}\text { Perceived } \\
\text { Usefulness }\end{array}$ & $\begin{array}{l}\text { monitoring technology in life } \\
\text { PU1: The extent to which remote } \\
\text { monitoring technology saves time } \\
\text { PU2 : he extent to which remote } \\
\text { monitoring technology improves } \\
\text { efficiency } \\
\text { PU3 : The extent to which remote } \\
\text { monitoring technology enhances the } \\
\text { quality of life } \\
\text { PU4 : The degree of usefulness of } \\
\text { remote monitoring technology in life }\end{array}$ & {$[1]$} \\
\hline Attitude & $\begin{array}{l}\text { ATT1 : Using remote monitoring } \\
\text { technology is a good idea } \\
\text { ATT2 : Using remote monitoring } \\
\text { technology is enjoyable } \\
\text { ATT3 : The extent to which I like to } \\
\text { use remote monitoring technology }\end{array}$ & [12] \\
\hline $\begin{array}{c}\text { Intention of } \\
\text { Use }\end{array}$ & $\begin{array}{l}\text { IU1: I would use remote monitoring } \\
\text { technology } \\
\text { IU2 : I would recommend remote } \\
\text { monitoring technology to my friends }\end{array}$ & {$[14]$} \\
\hline
\end{tabular}

\subsection{Survey Content and Method}

Firstly, this study is based on the TAM model, and the questionnaire suitable for this survey is designed for each index involved in the model. The survey content of the questionnaire includes two main aspects: (1) the influence of gender, age, education, and health status of the elderly on the intention to use remote monitoring technology, (2) the variables related to measuring remote monitoring technology: including perceived 
usefulness, perceived ease of use, attitude and intention of use. The observed variable entries were measured on a five-point Likert scale. In this study, the whole-group random sampling method was used to number the communities in Kunming where the pilot project of smart elderly care was carried out, and four communities were randomly selected using the lottery method, and the elderly people aged 60 years or older in the communities were used as the research subjects, and the questionnaire method was used to collect data. A total of 170 questionnaires were finally collected, and after eliminating invalid questionnaires, 150 valid questionnaires were recovered, with a suitable questionnaire recovery rate of $88.2 \%$.

\subsection{Statistical analysis method}

In this study, SPSS19. 0 software and AMOS24.0 software were used to analyze and statistically process the data. First, SPSS19. 0 software was used to test the reliability and validity of the questionnaire, independent sample t-test, and ANOVA analysis; then AMOS24.0 software was used to construct, test, and correct the model.

\section{RESEARCH RESULTS}

\subsection{Descriptive Statistics}

A total of 150 valid questionnaires were recovered from this survey. Among them, 62 (41.3\%) were male, and $88(58.7 \%)$ were female. The age of the respondents was mainly concentrated between 60-69 and 70-79 years old, each accounting for $45.3 \%$ and $33.3 \%$ of the total respondents. The education level was mainly distributed in elementary school and below, accounting for $50 \%$. The overall physical health was poor, $50.7 \%$ of the respondents indicated that they were weak and suffered from chronic diseases, $37.3 \%$ of the respondents said they were healthy, and $14 \%$ and $4 \%$ of the respondents showed some physical disabilities and suffered from serious diseases.

\subsection{Reliability and Validity Analysis}

SPSS 19.0 software was used for the reliability and validity analysis of this study. Firstly, the Cronbach's alpha coefficient values of each variable were used for the reliability test, and it was found that the Cronbach's alpha coefficient values of the variables involved in this study were all higher than the critical value of 0.7 , so the reliability test of the scale was passed. Then, the convergent validity and the discriminant validity of the data were analyzed. From Table 2, we can see that the AVE values of the variables involved in this study are higher than the critical value of 0.5 , which indicates that the data have good convergent validity. The measure of model discriminant validity is generally obtained by comparing the AVE values of the factors with the correlation coefficients of the other factors after cutting the square root. If the former is greater than the latter, it indicates a good discriminant validity [9]. It was found that the square root of the AVE of each variable was greater than the Pearson correlation coefficient of itself and the other variables, so the requirement of differential validity was satisfied. The results are shown in Table 2.

Table 2 convergence and discriminant validity of each variable

\begin{tabular}{|c|c|c|c|c|c|c|c|c|}
\hline \multirow{2}{*}{ Variables } & \multicolumn{2}{|c|}{ Convergent Validity } & \multirow{2}{*}{ Mean } & \multirow{2}{*}{ SD } & \multicolumn{4}{|c|}{ Discriminant Validity } \\
\hline & Cronbach's Alpha & AVE & & & PU & PEOU & ATT & IU \\
\hline $\mathrm{PU}$ & 0.922 & 0.815 & 3.262 & 0.748 & 0.903 & 0.526 & 0.693 & 0.725 \\
\hline PEOU & 0.956 & 0.885 & 2.822 & 1.016 & 0.526 & 0.941 & 0.788 & 0.642 \\
\hline ATT & 0.843 & 0.761 & 3.031 & 0.761 & 0.693 & 0.788 & 0.872 & 0.834 \\
\hline IU & 0.836 & 0.860 & 3.170 & 0.813 & 0.725 & 0.642 & 0.834 & 0.928 \\
\hline
\end{tabular}

Note: The bold diagonal is the square root of AVE, and the lower triangle is the Pearson correlation.

\subsection{Difference Analysis}

\subsection{1. $\quad$ Analysis of Gender Differences}

According to the results of the independent sample t-test, it can be seen that there is no significant difference in the perceived usefulness, attitude, and intention of using remote monitoring technology between male and female older adults. However, there is a significant difference in perceived ease of use, and comparing the mean values, it can be seen that the perceived ease of use of remote monitoring technology is somewhat higher for female older adults. The results are shown in Table 3. 
Table 3 Analysis of gender differences of each variable

\begin{tabular}{|c|c|c|c|c|c|c|}
\hline \multirow{2}{*}{ Variables } & \multicolumn{2}{|c|}{ Male } & \multicolumn{2}{|c|}{ Female } & \multirow{2}{*}{$t$} & \multirow{2}{*}{$p$} \\
\hline & Mean & SD & Mean & SD & & \\
\hline PU & 3.230 & 0.769 & 3.284 & 0.737 & -0.436 & 0.596 \\
\hline PEOU & 2.657 & 1.098 & 2.938 & 0.942 & -1.674 & $0.047^{*}$ \\
\hline ATT & 3.011 & 0.812 & 3.046 & 0.727 & -0.274 & 0.353 \\
\hline IU & 3.073 & 0.814 & 3.239 & 0.809 & -1.234 & 0.598 \\
\hline
\end{tabular}

Note: $* * * \mathrm{p}<0.001, * * \mathrm{p}<0.01, * \mathrm{p}<0.05$.

\subsection{2. $\quad$ Age Difference Analysis}

According to the results of the ANOVA analysis, it is clear that age has a significant effect on each latent variable. Comparing the mean values of each age group shows that the perceived usefulness, perceived ease of use, attitude, and intention to use remote monitoring technology of older adults decreases as age increases. The results are shown in Table 4.

Table 4 Analysis of age differences of each variable

\begin{tabular}{|c|c|c|c|c|c|c|c|c|c|c|}
\hline \multirow{2}{*}{ Variables } & \multicolumn{2}{|c|}{ 60 69 Years } & \multicolumn{2}{|c|}{ 70 79 Years } & \multicolumn{2}{|c|}{ 80 89 Years } & \multicolumn{2}{|c|}{$\geq 90$ Years } & \multirow{2}{*}{$\mathrm{F}$} & \multirow{2}{*}{$p$} \\
\hline & Mean & SD & Mean & SD & Mean & SD & Mean & SD & & \\
\hline PU & 3.415 & 0.682 & 3.175 & 0.643 & 2.853 & 0.952 & 3.317 & 0.947 & 3.017 & $0.032^{*}$ \\
\hline PEOU & 3.324 & 0.830 & 2.855 & 0.749 & 1.677 & 0.728 & 1.733 & 1.011 & 28.893 & $<0.001^{\star * *}$ \\
\hline ATT & 3.304 & 0.666 & 3.000 & 0.571 & 2.431 & 0.872 & 2.578 & 1.004 & 9.671 & $<0.001^{* * *}$ \\
\hline IU & 3.404 & 0.703 & 3.200 & 0.728 & 2.618 & 0.876 & 2.633 & 0.990 & 7.597 & $<0.001^{* * *}$ \\
\hline
\end{tabular}

Note: $* * * \mathrm{p}<0.001, * * \mathrm{p}<0.01, * \mathrm{p}<0.05$.

\subsubsection{Analysis of Differences in Education}

According to the results of the ANOVA analysis, it can be seen that education level has a significant effect on each latent variable. Comparing the means of different education levels shows that the perceived usefulness, perceived ease of use, attitude, and intention to use remote monitoring technology of the elderly increase with higher education level. The results are shown in Table 5.

Table 5 Difference analysis of education level of each variable

\begin{tabular}{|c|c|c|c|c|c|c|c|c|c|c|}
\hline \multirow{2}{*}{ Variables } & \multicolumn{2}{|c|}{ Primary school or below } & \multicolumn{2}{|c|}{ Junior high school } & \multicolumn{2}{|c|}{ Senior high school } & \multicolumn{2}{|c|}{ College degree or above } & \multirow{2}{*}{$\mathrm{F}$} & \multirow{2}{*}{$\mathrm{p}$} \\
\hline & Mean & $\mathrm{SD}$ & Mean & SD & Mean & SD & Mean & SD & & \\
\hline PU & 3.010 & 0.738 & 3.429 & 0.604 & 3.348 & 0.708 & 3.882 & 0.609 & 9.019 & $<0.001^{\star * *}$ \\
\hline PEOU & 2.220 & 0.867 & 2.964 & 0.754 & 3.545 & 0.569 & 3.921 & 0.692 & 35.982 & $<0.001^{* \star *}$ \\
\hline ATT & 2.640 & 0.706 & 3.226 & 0.622 & 3.429 & 0.452 & 3.702 & 0.666 & 20.419 & $<0.001^{* \star *}$ \\
\hline IU & 2.773 & 0.759 & 3.482 & 0.739 & 3.500 & 0.561 & 3.790 & 0.652 & 16.457 & $<0.001^{* * *}$ \\
\hline
\end{tabular}

Note: $* * * \mathrm{p}<0.001, * * \mathrm{p}<0.01, * \mathrm{p}<0.05$.

\subsubsection{Health Status Difference Analysis}

According to the results of ANOVA analysis, it can be seen that health status has a significant effect on perceived usefulness and perceived ease of use, and no significant impact on attitude and intention of use. Comparing the mean values of different health conditions, it can be seen that as the health condition 
decreases, the perceived usefulness of remote monitoring technology for the elderly shows an increasing trend, but the perceived ease of use shows a decreasing trend. The results are shown in Table 6 .

Table 6 Health status difference analysis of each variable

\begin{tabular}{|c|c|c|c|c|c|c|c|c|c|c|}
\hline \multirow{2}{*}{ Variables } & \multicolumn{2}{|c|}{ Health } & \multicolumn{2}{|c|}{ Weak, chronic disease } & \multicolumn{2}{|c|}{ Disability } & \multicolumn{2}{|c|}{ Critical illness } & \multirow{2}{*}{$\mathrm{F}$} & \multirow{2}{*}{$\mathrm{p}$} \\
\hline & Mean & SD & Mean & SD & Mean & SD & Mean & SD & & \\
\hline PU & 3.281 & 0.728 & 3.109 & 0.746 & 3.768 & 0.541 & 4.125 & 0.323 & 5.429 & $0.001^{* * *}$ \\
\hline PEOU & 2.996 & 1.019 & 2.862 & 0.919 & 2.196 & 1.260 & 1.813 & 0.657 & 3.886 & $0.01^{* *}$ \\
\hline ATT & 3.006 & 0.790 & 3.026 & 0.746 & 3.095 & 0.852 & 3.250 & 0.419 & 0.162 & 0.922 \\
\hline IU & 3.152 & 0.792 & 3.158 & 0.830 & 3.214 & 0.935 & 3.500 & 0.408 & 0.245 & 0.865 \\
\hline
\end{tabular}

Note: $* * * \mathrm{p}<0.001, * * \mathrm{p}<0.01, * \mathrm{p}<0.05$

\subsection{Structural Equation Model Analysis}

\subsubsection{Model Fitness Test and Correction}

In order to ensure the quality of the model, the goodness of fit of the model should be tested first before conducting hypothesis testing. The structural equation model is constructed using the software AMOS 24.0, and the initial model is estimated using the maximum likelihood method. The estimation results of the initial model showed that the MI values of residual paths such as "e9<-->e11" were larger, so the initial model was revised by adding the residual paths of "e $9<-->\mathrm{e} 11$ ", and the final results are shown in Table 7. The goodness-of-fit indicators all reach the best value range, indicating that the model fits well and can be used for path analysis. The final model is shown in Figure 2.

Table 7 Goodness of fit index of TAM model

\begin{tabular}{lllllll}
\hline Category & Absolute Fit & & & & Parsimonious Fit & Value-added Fit \\
\hline Measure & CMIN/DF & GFI & AGFI & RMSEA & PGFI & CFI \\
Threshold & $<3.0$ & $>0.85$ good & $>0.8$ good & $<0.05$ good & $>0.5$ good & $>0.95$ great \\
Value & 0.990 & 0.945 & 0.915 & 0.000 & 0.612 & 1.000 \\
\hline
\end{tabular}

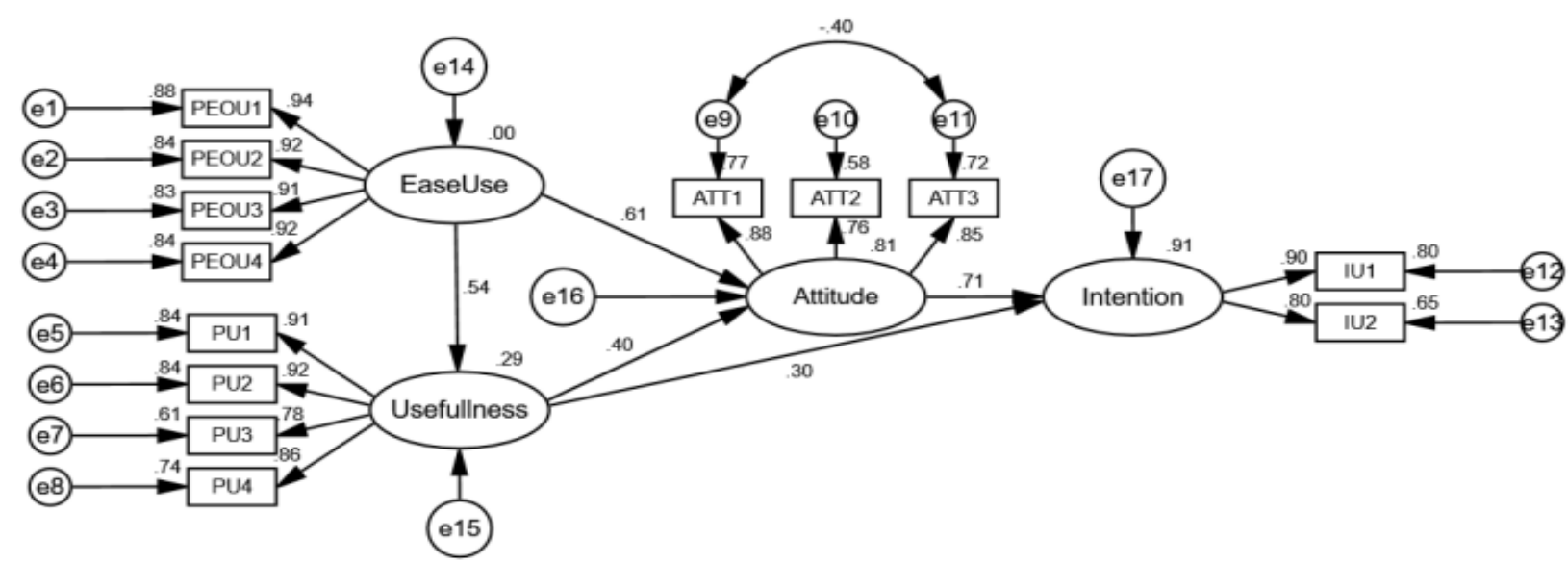

Figure 2. Modified TAM model of remote monitoring technology

\subsection{2. $\quad$ Model Path Analysis}

As can be seen from Table 8 , the unstandardized path coefficients between each latent variable are positive. And the effect of each independent variable on 
the dependent variable is significant according to the

p-value, so the hypotheses of this study are all valid.

Table 8 Path analysis and hypothesis verification

\begin{tabular}{|c|c|c|c|c|c|c|c|}
\hline & Path & & Estimate & S.E. & C.R. & $P$ & Hypothesis \\
\hline $\begin{array}{l}\text { Perceived } \\
\text { usefulness }\end{array}$ & $<---$ & $\begin{array}{l}\text { perceived ease of } \\
\text { use }\end{array}$ & 0.395 & 0.057 & 6.979 & $* * *$ & H1 Supported \\
\hline Attitude & $<---$ & $\begin{array}{c}\text { perceived ease of } \\
\text { use }\end{array}$ & 0.469 & 0.049 & 9.634 & $* * *$ & H2 Supported \\
\hline Attitude & $<---$ & $\begin{array}{l}\text { Perceived } \\
\text { usefulness }\end{array}$ & 0.423 & 0.064 & 6.647 & $* * *$ & H3 Supported \\
\hline intention of use & $<---$ & Attitude & 0.688 & 0.085 & 8.085 & $* * *$ & H4 Supported \\
\hline intention of use & $<---$ & $\begin{array}{l}\text { Perceived } \\
\text { usefulness }\end{array}$ & 0.302 & 0.080 & 3.792 & $* * *$ & H5 Supported \\
\hline
\end{tabular}

Note: $* * * \mathrm{p}<0.001, * * \mathrm{p}<0.01, * \mathrm{p}<0.05$.

\section{CONCLUSIONSAND RECOMMENDATIONS}

\subsection{Conclusions}

\subsubsection{Influence of Relevant Demographic Variables on Latent Variables}

Based on the results of the analysis of variance, the following conclusions can be drawn. Firstly, gender has a significant effect on the perceived ease of use of remote monitoring technology and no significant effect on other latent variables. Secondly, age and education have a significant effect on the perceived ease of use, perceived usefulness, attitude and intention of use. Thirdly, health status had a significant effect on the perceived ease of use and perceived usefulness of remote monitoring technologies, and no significant effect on attitudes and intention of use.

\subsubsection{The Relationship between The Latent Variable}

Based on the results of the structural equation modeling analysis, all five hypotheses proposed in this study have been verified. The conclusions are as follows: firstly, the perceived ease of use of remote monitoring technology by the elderly positively and significantly affects perceived usefulness. Secondly, the perceived ease of use of remote monitoring technology by the elderly positively and significantly affects attitude. Thirdly, the perceived usefulness of remote monitoring technology by the elderly positively and significantly affects attitude. Fourthly, the attitude of remote monitoring technology by the elderly positively and significantly affects intention of use. Fifthly, perceived usefulness of remote monitoring technology among older adults positively and significantly influences willingness to use. In addition, by comparing the standardized coefficients, it can be concluded that conclusion six: perceived ease of use (standardized path coefficient of 0.61) influences the attitude to a greater extent than perceived usefulness (standardized path coefficient of 0.30 ) influences the attitude. So perceived ease of use is the most important reason for the positive attitude toward remote monitoring technology among the elderly group.

\subsection{Recommendation}

Firstly, companies should conduct product development and functional innovation oriented to the perceived usefulness of the elderly. The initial reason for the elderly to use a technology or product is whether the product or service is helpful to their lives and satisfies their needs. Therefore, when companies innovate remote monitoring technology, they should first consider its usefulness and the degree of meeting customers' needs, and then they can stimulate users' use.

Secondly, companies should simplify the operation process and reduce the learning difficulty of relevant smart elderly products through technological innovation. Usefulness is a prerequisite for users to use a product or service, while ease of use is the key to continuous use. Due to age, education level, health condition, and other factors, the elderly have difficulties using information technology. Therefore, enterprises can simplify the operation process of products and services through technological innovation to eliminate the cognitive barriers caused by the "digital divide" and improve the user experience of the elderly.

Thirdly, enterprises should develop specific, smart products for seniors of different genders, ages, health conditions, and education levels. Since older people with other demographic characteristics have different 
perceptions and attitudes toward technology, we should not adopt a "one-size-fits-all" strategy in technological innovation. Still, we should provide precise services according to their individual needs to improve their quality of life in the evening.

\section{REFERENCES}

[1] Davis, F. D. (1989). Perceived Usefulness, Perceived Ease of Use, and User Acceptance of Information Technology. MIS Quarterly, 13(3), 319-340.

[2] Fisher, G. S., Baker, A., Koval, D., Lishok, C., \& Maisto, E. (2007). A field test of the Cougar Home Safety Assessment (version 2.0) in the homes of older persons living alone. Australian Occupational Therapy Journal, 54(2), 124-130.

[3] Fozard, J. L., \& Wahl, H. W. (2012). Age and cohort effects in gerontechnology: A reconsideration. Gerontechnology, 11(1).

[4] He, Y.-z., Zuo, M.-y., \& He, L. (2017). Factors Influencing Community Home Care Services Platforms Adoption by the Older People. Science and Management, 037(001), 54-64.

[5] He, Y., \& Xing, W. (2020). The Influencing Factors of the Adoption and Use Effectiveness of Smart Home-based Elderly Care Technology: A Literature Review Perspective. Journal of Information Resources Management

[6] Hoque, R., \& Sorwar, G. (2017). Understanding factors influencing the adoption of mHealth by the elderly: An extension of the UTAUT model. International Journal of Medical Informatics, 101(May), 75.

[7] Jia, Y., \& Wang, C. The Construction of Demand-Oriented Smart Home Care Service System. Inner Mongolia Social Sciences, 41(5), 8.
[8] Jiang, M., Li, J., \& Dai, F. (2020). Research Progress on Acceptance and Influencing Factors of Assistive Technology in the Elderly. Chinese Nursing Research, 34(13), 2334-2338.

[9] Li Jing, Guan Ziyu, Xie Fei, \& Qun, D. (2021). TAM-based Smart Medical APP User Sticky Model Construction and Technology Research. Journal of Northwest University(Natural Science Edition), 51(1), 24-32.

[10] Moon, Ji-Won, Kim, \& Young-Gul. (2001). Extending the TAM for a World-Wide-Web context. Information \& Management, 38(4), 217-217.

[11] Pavlou, \& A, P. (2003). Consumer Acceptance of Electronic Commerce: Integrating Trust and Risk with the Technology Acceptance Model. International Journal of Electronic Commerce, 7(3), 101-134.

[12] Taylor, S., \& Todd, P. A. (1995). Understanding Information Technology Usage : A Test of Competing Models. Information Systems Research, 5(2), 91-108.

[13] Tolulope A. Oyetunji M. D ., M. P. H., Sharon K. Ong'uti M. D ., M. P. H., Oluwaseyi B . Bolorunduro M. D ., M. P. H., Dani, O. G. B. S., D ., E. E. C. M., \& Adil H. Haider M. D ., M. P. H. (2012). Epidemiologic Trend in Elderly Domestic Injury. Journal of Surgical Research, 173(2), 206-211.

[14] Yu, Z., \& Song, P. (2017). Study on users' willingness to use NFC payment based on TAM-TOE model. Enterprise Economy, 36(06), 70-76. doi:10.13529/j.cnki.enterprise.economy.2017.06.01 1 